\title{
CAMPUR KODE BAHASA JEPANG OLEH PENUTUR BAHASA INDONESIA DI JEJARING SOSIAL FACEBOOK
}

\author{
Ni Luh Ernawati \\ Program Magister (S2) Linguistik \\ Program Pascasarjana Universitas Udayana \\ Jalan Nias No. 13 Denpasar 80114 \\ Ponsel: 081246668201 \\ ernamiura@yahoo.com
}

\begin{abstract}
Abstrak-Orang Indonesia yang mampu berbahasa Jepang sering kali memasukkan unsur bahasa Jepang ketika berkomunikasi dengan orang Indonesia yang juga mampu berbahasa Jepang, baik secara langsung maupun di jejaring sosial, seperti facebook. Fenomena kebahasaan ini dikupas berdasarkan konsep teori sosiolinguistik (campur kode). Sumber data primer penelitian ini adalah tuturan yang merupakan status ataupun komentar penutur bahasa Indonesia yang mengandung campur kode di facebook. Data sekunder didapat dari wawancara secara online dengan beberapa informan yang status dan komentarnya di facebook digunakan sebagai sumber data primer. Hasil analisis data menunjukkan bahwa jenis campur kode bahasa Jepang oleh penutur bahasa Indonesia di jejaring sosial facebook ditinjau dari unsur bahasa serapan yang digunakan adalah campur kode ke luar, sedangkan ditinjau dari tata tingkat perangkat kebahasaan adalah campur kode pada tataran kata, campur kode pada tataran frasa, dan campur kode pada tataran klausa. Faktor-faktor yang memengaruhi peristiwa campur kode tersebut, yaitu (1) penutur ingin mempraktikkan bahasa Jepang; (2) terdapat unsur bahasa Jepang yang tidak bisa diinterpretasikan $100 \%$ ke dalam bahasa Indonesia; (3) penutur satu komunitas dengan mitra tutur; (4) dapat memancing mitra tutur untuk menggunakan bahasa Jepang; (5) agar lebih keren; (6) menghindari kevulgaran, dan (7) hal-hal yang dikomunikasikan berkaitan dengan Jepang.
\end{abstract}

\section{Kata kunci: bahasa Jepang, campur kode, facebook}

Abstract_Indonesian people who can speak Japanese language often mix elements of Japanese language when communicating with the people of Indonesia who is also able to speak Japanese languange either directly or on social networks like facebook. This linguistic phenomenon peeled sociolinguistic theory based on the concept of code mixing. The primary data source is utterances which was updated status and comments of Indonesian people that contain code mixing on facebook. The secondary data were obtained from the online interviews with several informants who their updated status or comments of facebook were used for the primary data source.The results of the data analysis showed that the type of code mixing of the Indonesian on facebook in terms of element uptake language used is outer code mixing, while in terms of system -level linguistic device are clauses code mixing, phrases code mixing, and words code mixing. The factors that influence the event of code mixing are (1) speaker wants to practice Japanese language that they learned; (2) there are some elements of Japanese language that can not be interpreted $100 \%$ to Indonesian language; (3) speaker is one community with the patner; (4) can 
provoke the patner to use Japaese language; (6) to be more cool (7) the things that was communicated was related to the Japan.

Keywords: Japaese language, code mixing, facebook

\section{PENDAHULUAN}

Belajar bahasa asing seperti bahasa Inggris sebagai bahasa internasional, bahasa Jepang, dan bahasa asing lainnya sangat diperlukan pada era global seperti sekarang ini. Proses komunikasi akan menjadi lebih kompleks dengan penggunaan bahasa asing yang bukan merupakan bahasa ibu atau bahasa nasional. Komunikasi adalah hubungan kontak antar dan antara manusia baik individu maupun kelompok (Widjaja, 2010: 1). Komunikasi akan berjalan dengan baik jika seseorang penutur yang terlibat dalam komunikasi tersebut dapat memosisikan diri dalam menggunakan bahasa dengan siapa ia berkomunikasi. Seorang pembelajar bahasa asing pada umumnya akan berusaha mempraktikkan pengetahuan yang didapat di sekolah atau kampus agar lebih cepat menguasai bahasa asing tersebut. Ketika ingin memperaktikkan bahasa asing, seseorang akan sering mencampurkan unsur bahasa asing ke dalam suatu bahasa. Kondisi pencampuran bahasa seperti itu muncul karena berbagai faktor, misalnya situasi tertentu yang memaksa seseorang harus menggunakan bahasa lain atau kode lain ketika ia sedang berbicara dengan bahasa tertentu, situasi ketika seseorang ingin menegaskan sesuatu, dan hal itu hanya bisa dilakukan dengan menggunakan bahasa lain, ataupun keinginan seseorang untuk membuat tuturannya menjadi lebih menarik. Peristiwa pencampuran bahasa itu disebut dengan istilah campur kode.

Sebelum dikupas tentang campur kode sebaiknya diketahui terlebih dahulu tentang kode, di mana Wardhaugh (1986:99) menyatakan bahwa kode sebagai sebuah sistem yang digunakan untuk berkomunikasi antara dua penutur atau lebih yang berupa sebuah dialek atau bahasa tertentu. Kemudian campur kode adalah digunakannya unsur suatu bahasa di mana penuturnya secara pokok menggunakan bahasa lain (Fasold, 1984: 180--183). Fasold menambahkan bahwa seorang penutur dikatakan mencampur kode apabila menggunakan kata atau frasa dari bahasa lain ke dalam bahasa pokok. Akan tetapi, jika penutur menggunakan satu klausa yang memiliki struktur gramatikal dari satu bahasa dan selanjutnya dikonstruksi sesuai dengan gramatika yang lain maka itu dapat dikatakan mengalih kode. Gumperz (dalam Ibrahim, 1993: 60) menyebutkan bahwa unsur atau serpihan bahasa yang diambil dari bahasa lain bisa kata, frasa atau unit yang lebih luas. Chaer (2007: 69) memberikan pengertian bahwa campur kode adalah digunakanya dua kode atau lebih tanpa alasan dan biasanya terjadi tanpa sebab. Selanjutnya, Kridalaksana (2008: 41) menjelaskan bahwa campur kode adalah penggunaan satuan bahasa dari satu bahasa ke bahasa lain untuk memperluas gaya bahasa atau ragam bahasa termasuk di dalamnnya pemakaian kata, klausa, idiom, dan sapaan. Nababan (1993:32) menjelaskan bahwa campur kode adalah pencampuran dua atau lebih bahasa atau ragam bahasa dalam suatu tindak bahasa (speech act atau discourse) tanpa ada sesuatu dalam situasi berbahasa itu yang menuntut pencampuran bahasa itu. Selanjutnya, Jendra (1991:130) memaparkan bahwa timbulnya campur kode merupakan akibat adanya kontak bahasa dan saling ketergantungan bahasa (language dependency), ada unsur bahasa lain dalam suatu bahasa. 
Secara umum campur kode dibedakan menjadi dua, yaitu berdasarkan sudut bahasa serapan yang menimbulkan terjadinya campur kode dan berdasarkan tata tingkat perangkat bahasa yang digunakan dalam campur kode (Jendra, 1991: 132). Berdasarkan sudut unsur bahasa yang menimbulkan terjadinya campur kode itu, campur kode dibedakan menjadi dua, yaitu campur kode ke dalam (inner code-mixing), dan campur kode ke luar (outer codemixing). Berdasarkan tata tingkat perangkat bahasa yang digunakan dalam campur kode itu, campur kode dibedakan menjadi tiga, yaitu campur kode pada tataran kata, campur kode pada tataran frasa, dan campur kode pada tataran klausa.

Fenomena campur kode banyak ditemukan dalam proses komunikasi yang multilingual. Salah satu contoh yang paling terkini seiring dengan perkembangan zaman adalah proses campur kode bahasa asing oleh penutur bahasa Indonesia di jejaring sosial facebook. Seperti diketahui bahwa jejaring sosial facebook sangat digandrungi oleh sebagian besar masyarakat khususnya anak muda. Mereka merasa akan ada yang kurang jika tidak membuka facebook selama sehari, sejam, bahkan semenit. Dalam menyampaikan tuturannya pun penutur bahasa Indonesia yang masih tergolong pemula dalam belajar bahasa asing ataupun yang sudah mahir berbahasa asing akan sering mencampur kode bahasa asing ketika berkomunikasi dengan sesama pembelajar bahasa asing. Peristiwa campur kode itu juga sering terjadi pada penutur bahasa Indonesia pembelajar bahasa Jepang. Mereka sering memasukkan unsur bahasa Jepang ke dalam bahasa Indonesia di jejaring sosial facebook.

Berdasarkan latar belakang di atas, masalahmasalah dalam penelitian ini dapat dirumuskan sebagai berikut. Pertama, jenis campur kode apa sajakah yang ditemukan dalam campur kode bahasa Jepang oleh penutur bahasa Indonesia di jejaring sosial facebook? Kedua, faktor apa sajakah yang memengaruhi campur kode bahasa Jepang oleh penutur bahasa Indonesia di jejaring sosial facebook?

Tujuan penelitian ini adalah untuk mendeskripsikan jenis-jenis campur kode bahasa Jepang oleh penutur bahasa Indonesia di jejaring sosial facebook dan menelaah faktor-faktor yang memengaruhinya. Sementara itu, manfaat teoretis penelitian ini adalah untuk menambah khazanah informasi kelinguistikan khususnya sosiolinguistik yaitu campur kode. Sebaliknya, manfaat praktis penelitian ini adalah memberikan informasi tentang campur kode bahasa Jepang yang digunakan oleh penutur bahasa Indonesia di jejaring sosial facebook. Penelitian ini juga bermanfaat secara praktis sebagai bahan ajar tambahan mengenai kosakata bahasa Jepang, mengingat sebagian besar orang menggunakan facebook. Dengan adanya tambahan campur kode bahasa Jepang di status facebook-nya, maka pembelajar bahasa Jepang akan lebih cepat menghafal dan mengingat kosakata bahasa Jepang.

\section{METODE PENELITIAN}

Penelitian ini bersifat deskriptif dengan pendekatan kualitatif. Data kualitatif penelitian ini adalah data tuturan yang bersumber dari jejaring sosial facebook yang diunggah pada tahun 2014. Data tuturan ini termasuk data primer. Selain data primer, data juga diperoleh dari data pununjang atau pendukung. Data penunjang yang dimaksud adalah data yang dimanfaatkan untuk menunjang kerja analisis (Mastoyo, 2007:26). Data penunjang atau data sekunder adalah wawancara online dengan 
beberapa informan yang status ataupun komentarnya di facebook dikutip dan digunakan sebagai data primer.

Metode yang digunakan dalam penelitian ini adalah metode simak dan metode cakap. Sudaryanto (1988: 2) menyatakan bahwa metode simak atau penyimakan dilakukan dengan cara menyimak penggunaan bahasa. Sedangkan metode cakap merupakan metode yang dilakukan dengan cara kontak antara peneliti dan informan. Teknik pengumpulan data dilakukan dengan cara pengamatan, penyimakan status dan komentar tuturan-tuturan yang mengandung campur kode di facebook. Kemudian, peneliti mencatat data tuturan yang dipilih. Metode cakap yang digunakan adalah metode cakap tansemuka, yaitu peneliti mengirimkan beberapa daftar tanyaan secara online melalui facebook kepada beberapa informan yang status ataupun komentarnya di facebook dikutip dan digunakan sebagai data. Daftar tanyaan berkaitan dengan faktor-faktor yang memengaruhi informan melakukan campur kode tersebut. Selanjutnya metode yang digunakan pada analisis data adalah metode agih. Metode agih adalah metode yang alat penentunya bagian dari bahasa yang diteliti (Sudaryanto, 1993:15).

\section{PEMBAHASAN}

Campur kode bahasa Jepang yang dilakukan oleh penutur bahasa Indonesia sering kali terjadi di jejaring sosial facebook. Campur kode tersebut muncul ketika penutur mengunggah statusnya sendiri ataupun mengomentari status teman-teman facebooknya. Sebagian besar dari penutur tersebut adalah akademisi bahasa Jepang penutur bahasa Indonesia, seperti mahasiswa, para dosen, dan sebagainya. Ada beberapa nama akun facebook penutur tersebut menggunakan nama Jepang. Berikut adalah data campur kode bahasa Jepang yang dilakukan oleh penutur bahasa Indonesia di jejaring sosial facebook.

\section{Campur Kode pada Tataran Kata Data 1 \\ 頑張ってMBAKU (Hasby Riduan, 24 Mei 2014)}

Ganbatte Mbaku

'Semangatlah Mbaku'

Data 1 di atas merupakan sebuah komentar status yang diunggah di facebook, yaitu dukungan yang diberikan oleh Riduan kepada temannya yang sedang menempuh pendidikan di Jepang. Orang Indonesia, yaitu Riduan mencampur kode bahasa Jepang ganbatte untuk menggantikan bahasa Indonesia semangat. Kata ganbatte termasuk verba yang bentuk kamusnya adalah ganbaru. Ganbaru adalah verba golongan I dalam bahasa Jepang, di mana proses perubahannya melalui renyoukei. Renyoukei merupakan perubahan bentuk verba yang termasuk bentuk sopan (bentuk masu), bentuk sambung (bentuk te), dan bentuk lampau (bentuk ta) (Sutedi, 2008:49). Pada data tuturan 1 di atas verba ganbatte berfungsi sebagi bentuk perintah. Proses perubahannya yaitu, ganba-ru $\rightarrow$ ganba-tte. Penggunaan huruf kanji pada kata ganbatte di atas diseabkan oleh orang yang diberikan semangat oleh Riduan memiliki latar belakang yang sama, yaitu sama-sama pembelajar dan pengguna bahasa Jepang.

\section{Data 2}

(2.1) Sudahlah! Oyasumi (Yukari Yabuhirota, 19 Mei 2014)

'Sudahlah! Selamat malam dan selamat beristirahat'

(2.2) Tuh kan anak Gede dh marah,,, Ayoo anak kecil kita bobo, 
Ehehee,Oyasuminasai. (Antara Aida, 21 Mei 2014)

'Tuh kan anak gede sudah marah, ayo anak kecil kita bobok, hehe, selamat malam dan selamat beristirahat'

Data (2.1) merupakan status facebook Yabuhirota, sedangkan data (2.2) merupakan komentar status facebook yang diunggah oleh Aida, yang ditujukan kepada seorang dosen bahasa Jepang yang mengunggah sebuah foto kegiatan sosial di daerah Pulau Serangan. Kedua data tuturan di atas mencampur kode bahasa Jepang oyasuminasai untuk menggantikan bahasa Indonesia selamat malam dan selamat beristirahat. Oyasumi dan oyasuminasai memiliki arti yang sama, hanya oyasumi adalah bentuk informal, sedangkan oyasuminasai adalah bentuk formal atau lebih halus. Seperti yang dijelaskan oleh Tsujimura (1996:410) bahwa speech level atau tingkatan berbahasa sangat diperlukan menyesuaikan dengan siapa kita berbicara. Jika berbicara dengan atasan seperti dosen atau professor, pembicara akan menggunakan kata formal atau yang lebih halus.

\section{Data 3}

(3.1) Sugoi, lumayan mirip lha bagus lisachan ayo lanjutkan (Komentar

Anasicha Archuleta, 15 Mei 2014)

'Hebat, lumayan mirip lha bagus Lisa ayo lanjutkan'

(3.2) Group D sibuk bgt ampe ga ketangkep kamera すごいよ。（“O

(Fitri Lestari, 21 April 2014)

'Group D sibuk bgt ampe ga ketangkep kamera sugoiyo. ( ${ }^{\wedge} \mathrm{O}{ }^{\wedge}$ )

'Group D sibuk banget sampai tidak tertangkap kamera, hebat lo'

Data (3.1) merupakan status facebook yang diunggah oleh Archuleta, ditujukan kepada teman facebook-nya yang mengunggah sebuah foto tentang gambar hasil karya temannya tersebut. Demikan juga data (3.2) merupakan status facebook Lestari yang ditujukan kepada temannya yang mengunggah video tentang kegiatan sosial di Pulau Serangan. Dalam video tersebut juga terdapat dirinya dengan grupnya, yaitu grup $\mathrm{D}$, yang menjadi pemenang dalam kegiatan beberapa lomba yang diadakan di Pulau Serangan. Kedua data di atas mencampur kode bahasa Jepang sugoi, menggantikan kode bahasa Indoneisa hebat. Sugoi yo pada data (3.2) terdiri atas adjektiva sugoi + partikel yo yang artinya hebat lo. Penggunaan partikel yo merupakan ciri bahasa perempuan dalam bahasa Jepang. Penggunaan huruf hiragana pada kata sugoi yo (data 3.2) disebabkan oleh mitra tuturnya pada situasi tutur di atas adalah sama-sama menggunakan huruf Jepang ketika mencampur kode bahasa Jepang.

\section{Data 4}

Bnyk pengunjung blg liat hantu anak2 unyu2 gtu..perasaan ga ada anak2 jd obake :| kalau pun bnran "mereka" beneran nongol plg ga tersamarkan krna pengunjung kira merka bohongan :| (Megaristy Zefanya, 6 Mei 2014)

'Banyak pengunjung mengatakan melihat hantu ana-anak unyu-unyu gitu..perasaan tidak ada anak-anak jd hantu :| kalau pun beneran "mereka" beneran nongol pulang tidak tersamarkan karena pengunjung kira mereka bohongan :|'

Data 4 merupakan komentar facebook yang diunggah oleh Zefanya. Komentar tersebut ditujukan kepada temannya yang mengunggah sebuah status tentang hasil kegiatan festival budaya Jepang yang diadakan di Stiba Saraswati Denpasar. Dalam kegiatan tersebut banyak ditampilkan budaya Jepang dan terdapat beberapa 
perpaduan budaya Indonesia. Salah satu kegiatannya ialah mendirikan rumah hantu. Pada data di atas, Zefanya mencampur kode bahasa Jepang obake 'hantu' untuk menggantikan bahasa Indonesia hantu. Obake termasuk ke dalam jenis nomina. Obake merupakan jenis nomina konkret. Sudjianto (2004:38) menjelaskan bahwa nomina dalam bahasa Jepang disebut dengan meishi. Jenis meishi dibedakan menjadi gutaitekina mono (nomina konkret), chuushoutekina mono (nomina abstrak), ichi ya hougaku o shimesu mono (nomina yang menyatakan letak, posisi, kedudukan, dan arah), settogo ya setsubigo no tsuita mono (nomina yang disisipi prefiks, atau sufiks), fukugou meishi (nomina majemuk), dan hoka no hinshi kara tenjita mono (nomina yang berasal dari kelas kata lain).

\section{Data 5}

Iya, saluuuuutt banget buat kerja keras panitia.. Saya masih kebayang wajah-wajah kalian yang penuh kerja keras mempersiapkan semuanya, tak akan sensei lupa ${ }^{\wedge}$ (Betty Aritonang, 6 Mei 2014)

'Iya, saluuuuutt banget buat kerja keras panitia.. Saya masih kebayang wajah-wajah kalian yang penuh kerja keras mempersiapkan semuanya, tak akan guru lupa $\wedge^{\wedge}$,

Data 5 merupakan status facebook yang diunggah oleh seorang pengajar yaitu dosen. Komentar itu ditujukan kepada status facebook salah seorang mahasiswa yang merupakan ketua panitia festival budaya Jepang. Status facebook mahasiswa itu merupakan status ucapan terima kasih kepada semua orang yang terkait dalam kegiatan tersebut. Pada data 5, seorang dosen mencampur kode bahasa Jepang sensei 'guru' (Matsuura, 2005: 887) untuk menggantikan bahasa Indonesia guru, dosen, pengajar akademis. Kata sensei termasuk ke dalam jenis nomina.

\section{Data 6}

Gomen, saya hr sabtu ad acara keluarga. hari minggunya diusahakan.. (Intan Widyastini Jaya, 9 Mei 2014)

'Maaf, saya hari Sabtu ada acara keluarga. Hari Minggunya diusahakan.'

Data 6 merupakan komentar facebook yang diunggah oleh Widyastini untuk mengomentari status teman facebooknya yang menginformasikan tentang jadwal rapat persiapan kegiatan sosial (Komunitas Peduli Pendidikan Anak). Akan tetapi, Widyastini tidak bisa berpartisipasi. Pada data 6 di atas, Widyastini memasukkan unsur bahasa Jepang gomen untuk menggantikan kata bahasa Indonesia maaf.

\section{Data 7}

パソコン ini semakin lelet saja. Apa gara2 jarang tak bersihin yaw. Kudu disayang nie karang. Ap jd nya lok kerjaan ga ad si パソコン???? (Eka Kurnia, 26 Mei 2014)

Pasokon ini semakin lelet saja. Apa gara2 jarang tak bersihin yaw. Kudu disayang nie karang. Ap jd nya lok kerjaan ga ad si pasokon????

'Komputer ini semakin lelet saja. Apa gara2 jarang tak bersihin yaw. Kudu disayang nie karang. Apa jadinya lok kerjaan ga ada si komputer????

Data 7 merupakan status Kurnia di facebook. Kurnia mencampur kode bahasa Jepang pasokon untuk menggantikan kode bahasa Indonesia komputer. Kata pasokon termasuk ke dalam jenis kata nomina. Penggunaan huruf katakana pada kata pasokon di atas disebabkan oleh kata tersebut merupakan kata serapan dari bahasa Inggris personal computer. 
Vol. 49. No. 25

Selain data yang telah dianalisis di atas, terdapat beberapa data campur kode pada tataran kata yang ditemukan, seperti tabel berikut.

Tabel 1: Campur Kode bahasa Jepang pada Tataran Kata

\begin{tabular}{|c|c|c|c|c|}
\hline $\begin{array}{l}\mathbf{N} \\
\mathbf{0}\end{array}$ & $\begin{array}{l}\text { Unsur } \\
\text { bahasa } \\
\text { Jepang } \\
\text { yang } \\
\text { dicampur } \\
\text { kodekan } \\
\end{array}$ & $\begin{array}{l}\text { Arti } \\
\text { dalam } \\
\text { bahas } \\
\text { a } \\
\text { Indon } \\
\text { esia } \\
\end{array}$ & $\begin{array}{l}\text { Pengu } \\
\text { nggah }\end{array}$ & $\begin{array}{l}\text { Tangg } \\
\text { al dan } \\
\text { tahun } \\
\text { mengu } \\
\text { nggah }\end{array}$ \\
\hline 1 & senpai & senior & $\begin{array}{l}\text { Ayu } \\
\text { Suryan } \\
\text { i }\end{array}$ & $\begin{array}{l}6 \quad \text { Mei } \\
2014\end{array}$ \\
\hline 2 & bunkasai & $\begin{array}{l}\text { festiva } \\
1 \\
\text { buday } \\
\text { a } \\
\text { Jepang }\end{array}$ & $\begin{array}{l}\text { Cherin } \\
\underline{\text { ata }} \\
\underline{\text { Isna }}\end{array}$ & $\begin{array}{l}3 \quad \text { Mei } \\
2014\end{array}$ \\
\hline 3 & hana & bunga & $\frac{\frac{\text { Fitria }}{\text { Nakam }}}{\text { ura }}$ & $\begin{array}{l}6 \quad \text { Mei } \\
2014\end{array}$ \\
\hline 4 & okane & uang & $\frac{\text { Antara }}{\text { Aida }}$ & $\begin{array}{l}6 \quad \text { Mei } \\
2014\end{array}$ \\
\hline 5 & Kokoro & Hati & $\begin{array}{l}\text { Mang } \\
\text { Karang }\end{array}$ & $\begin{array}{l}10 \text { Mei } \\
2014\end{array}$ \\
\hline 6 & higaeri & $\begin{array}{l}\text { pulang } \\
\text { pergi } \\
\text { sehari }\end{array}$ & $\frac{\text { S-Rio }}{\underline{\text { Zendi }}}$ & $\begin{array}{l}20 \text { Mei } \\
2014\end{array}$ \\
\hline 7 & Nouken & $\begin{array}{l}\text { tes } \\
\text { kema } \\
\text { mpuan }\end{array}$ & $\frac{\text { S-Rio }}{\underline{\text { Zendi }}}$ & $\begin{array}{l}20 \text { Mei } \\
2014\end{array}$ \\
\hline 8 & waza-waza & $\begin{array}{l}\text { Sengaj } \\
\text { a }\end{array}$ & $\begin{array}{l}\text { Katya } \\
\text { Alvina } \\
\text { Canaky } \\
\text { a }\end{array}$ & $\begin{array}{l}20 \text { Mei } \\
2014\end{array}$ \\
\hline 9 & shuukatsu & $\begin{array}{l}\text { menca } \\
\text { ri } \\
\text { pekerj } \\
\text { aan }\end{array}$ & $\begin{array}{l}\text { Katya } \\
\text { Alvina } \\
\text { Canaky } \\
\text { a }\end{array}$ & $\begin{array}{l}20 \text { Mei } \\
2014\end{array}$ \\
\hline 1 & Kenkyu & Penelit & Katya & 20 Mei \\
\hline
\end{tabular}

\begin{tabular}{lllll}
\hline $\mathbf{0}$ & & ian & $\begin{array}{l}\text { Alvina } \\
\text { Canaky }\end{array}$ & 2014 \\
& & & a & \\
$\mathbf{1}$ & Neechan & kakak & $\underline{\text { Ita }}$ & $26 \mathrm{Mei}$ \\
$\mathbf{1}$ & & $\begin{array}{l}\text { perem } \\
\text { puan }\end{array}$ & $\underline{\text { Regina }}$ & 2014 \\
& & Tolon & Yukari & $16 \mathrm{Mei}$ \\
$\mathbf{1}$ & onegai & g & Yabuhi & 2014 \\
$\mathbf{2}$ & & pata & \\
$\mathbf{1}$ & Ryoukai & paham & $\underline{\text { Maylan }}$ & $12 \mathrm{Mei}$ \\
$\mathbf{3}$ & & & $\underline{\text { Geulis }}$ & 2014 \\
\hline
\end{tabular}

Campur Kode pada Tataran Frasa

\section{Data 8}

Ini nulis puisinya saat nunggu bis di depan toyohashi eki setelah nyusha shiki komchan (Fitria Nakamura, 6 Mei 2014)

'Ini nulis puisinya saat nunggu bis di depan Stasiun Toohashi setelah upacara mulai masuk kerja komchan'

Data 8 merupakan sebuah komentar status facebook yang diunggah oleh Nakamura. Ia mengomentari komentar orang yang mengomentari statusnya sendiri. Status Nakamura memuat puisi yang ditulis di sebuah stasiun di Jepang. Pada data 10, Nakamura mencampur kode bahasa Jepang Toyohashi eki untuk menggantikan stasiun Toyohashi dan nyusha shiki menggatikan upacara mulai masuk kerja.

\section{Data 9}

ホットケーキbaru ada ernasan (Fitria Nakamura, 21 April 2014)

\section{Hotto ke-ki baru ada Erna san}

'Kue panas baru ada Erna san'

Data 9 merupakan komentar status facebook yang diunggah oleh Nakamura. Nakamura menggunakan frasa hotto ke-ki dalam bahasa Indonesia untuk mengantikan kue panas. Penggunaan huruf katakana pada kata hotto $k e-k i$ di atas disebabkan oleh kata tersebut 
merupakan kata serapan dari bahasa Inggris hot cake.

\section{Data 10}

Di sini nggak ada batas hurufnya sih, tapi kebanyakan untuk レポート・トラック sekitar 10 halaman. 論文トラック ya kayak skripsi. (Katya Alvina Canakya, 25 Mei 2014)

Di sini nggak ada batas hurufnya sih, tapi kebanyakan untuk repo-to torakku sekitar 10 halaman. Ronbun torakku ya kayak skripsi.

'Di sini nggak ada batas hurufnya sih, tapi kebanyakan untuk laporan setruk sekitar 10 halaman. Paper setruk ya kayak skripsi.'

Data 10 merupakan komentar status facebook yang diunggah oleh Canakya. Ia dan temannya membahas pendidikan yang ditempuh di Jepang. Mereka saling menceritakan bagaimana tugas-tugas kampus yang diberikan oleh dosen mereka. Canakya menuntut ilmu di daerah Osaka, Jepang, sedangkan temannya di daerah Kumamoto, Jepang. Sistem belajar mereka sedikit berbeda. Canakya, dalam data tuturan di atas, menggunakan frasa repo-to torakku untuk menggantikan laporan setruk dan ronbun torakku untuk menggantikan paper setruk. Penggunaan huruf katakana pada kata repo-to torakku dan torakku pada kata ronbun torakku disebabkan oleh ketiga kosakata tersebut merupakan serapan dari bahasa Inggris. Sementara itu penggunaan huruf kanji pada kata ronbun disebabkan oleh kata ronbun merupakan huruf asli bahasa Jepang.

Selain data yang telah dianalisis di atas, terdapat beberapa data campur kode pada tataran frasa yang ditemukan, seperti tabel berikut.

Tabel 2: Campur Kode Bahasa Jepang pada Tataran Frasa

\begin{tabular}{|c|c|c|c|c|}
\hline $\begin{array}{l}\mathbf{N} \\
\mathbf{o}\end{array}$ & $\begin{array}{l}\text { Unsur } \\
\text { bahasa } \\
\text { Jepang yang } \\
\text { dicampurko } \\
\text { dekan }\end{array}$ & $\begin{array}{l}\text { Arti dalam } \\
\text { bahasa } \\
\text { Indonesia }\end{array}$ & $\begin{array}{l}\text { Pengu } \\
\text { nggah }\end{array}$ & $\begin{array}{l}\text { Tanggal } \\
\text { dan tahun } \\
\text { mengungga } \\
\text { h }\end{array}$ \\
\hline 1 & $\begin{array}{l}\text { Watashi no } \\
\text { baka }\end{array}$ & $\begin{array}{l}\text { kebodohan } \\
\text { saya }\end{array}$ & $\begin{array}{l}\text { Anik S. } \\
\text { Rahayu }\end{array}$ & $\begin{array}{l}31 \text { Agustus } \\
2014\end{array}$ \\
\hline 2 & $\begin{array}{l}\text { Itsumo } \\
\text { ganbaru }\end{array}$ & $\begin{array}{l}\text { Selalu } \\
\text { semangat }\end{array}$ & $\begin{array}{l}\text { Erika } \\
\text { Putri } \\
\text { Gustia } \\
\text { na }\end{array}$ & 7 Juli 2014 \\
\hline 3 & $\begin{array}{l}\text { Iro-irona } \\
\text { minzoku ishu }\end{array}$ & $\begin{array}{l}\text { Berbagai } \\
\text { pakaia adat }\end{array}$ & $\begin{array}{l}\frac{\text { Yukiko }}{\text { Nabila }} \\
\text { Putri }\end{array}$ & $\begin{array}{l}\text { 1 September } \\
2014\end{array}$ \\
\hline 4 & $\begin{array}{ll}\text { Ichinen } & \text { no } \\
\text { ryuugaku } & \end{array}$ & $\begin{array}{ll}\text { Studi ke luar } \\
\text { negeri } & \text { satu } \\
\text { tahun } & \end{array}$ & $\frac{\text { Rio }}{\text { Zendi }}$ & $\begin{array}{l}11 \\
\text { September } \\
2014\end{array}$ \\
\hline 5 & $\begin{array}{l}\text { Sotsugyou no } \\
\text { hi }\end{array}$ & $\begin{array}{l}\text { Hari } \\
\text { kelulusan }\end{array}$ & $\begin{array}{l}\frac{\text { Yukiko }}{\text { Nabila }} \\
\text { Putri }\end{array}$ & $\begin{array}{l}14 \\
\text { September } \\
2014\end{array}$ \\
\hline
\end{tabular}

\section{Campur Kode pada Tataran Klausa} Data 11

Fitria Nakamura braninya cuma main jewer, ga seruu ,,kompyang Supartini Ciieehhh kitto senpai no oshiri kara hana wo deteru Ehehhee (Antara Aida, 6 Mei 2014)

'Fitria Nakamura braninya cuma main jewer, ga seruu ,,kompyang Supartini Ciieehhh pasti akan keluar bunga dari pantat senior Ehehhee'

Data 11 merupakan komentar status facebook yang ditujukan kepada temannya yaitu Supartini. Ia menggunakan klausa kitto senpai no oshiri kara hana wo deteru untuk menggantikan bahasa Indonesia pasti akan keluar bunga dari pantat senior.

Data 12

Omedetou brow..来年一番ね。 sapa juara satu? (Rijaya Putra, 4 Mei 2014)

Omedetou brow..rainen ichiban ne sapa juara satu?

'Selamat brow.. tahun depan jadi nomer satu iya 。 sapa juara satu?'

Data 12 merupakan komentar status yang diunggah oleh Putra, ditujukan kepada temannya yang pada saat itu menjadi juara dua dalam pidato bahasa Jepang tingkat 
provinsi yang dilaksanakan oleh Japan Foundation. Putra memberikan selamat kepada temannya dengan menggunakan kata omedetou. Selanjutya penggunaan frasa bahasa Jepang rainen ichiban ne untuk menggantikan bahasa Indonesia tahun depan menjadi yang nomer satu iya. Penggunaan huruf kanji pada klausa rainen ichiban ne disebabkan oleh klausa tersebut terbentuk dari kata asli bahasa Jepang.

\section{Data 13}

Senyum" ndiri jadi nyaa ,,Minna arigatou (Antara Aida, 21 April)

'Senyum" ndiri jadi nyaa ,,terima kasih semuanya'

Data 13 merupakan komentar status facebook yang diunggah oleh Aida, ditujukan kepada status temannya. Aida menggunakan klausa minna arigatou dalam bahasa Jepang untuk menggantikan klausa semuanya terima kasih dalam bahasa Indonesia. Mengucapkan terima kasih menjadi tradisi orang Jepang, demikian juga orang Indonesia yang belajar bahasa Jepang akan mempelajari budayanya juga sehingga sebagian besar pembelajar bahasa Jepang akan menerapkan budaya Jepang yang dipelajarinya dalam kehidupan sehari-hari.

\section{Data 14}

Arigatou Pastiarini Nyoman sensei atas bimbingan drama ny slama beberapa bln ini arigatou Fitria Nakamura sensei dan satoshi san sudah di bantu buat video dramanya. smoga hasilny bagus ya ...jd gak sbar nton video ny 皆さんお疲れ様でした ..men sari, pan sari, nengah kun, luh, mang, yun, rin, nana, anjani, yuna, yuri sensei, airin sensei, shiki dancer, shiki souran..abdi,gek,krisna, pkoknya semuanya - feeling wonderful at Gedung Pers K.Nadha. (UniQue Yunitha, 12 April 2014)
Arigatou Pastiarini Nyoman sensei atas bimbingan drama ny slama beberapa bln ini arigatou Fitria Nakamura sensei dan satoshi san sudah di bantu buat video dramanya. smoga hasilny bagus ya ...jd gak sbar nton video ny minasan otsukaresama deshita ..men sari, pan sari, nengah kun, luh, mang, yun, rin, nana, anjani, yuna, yuri sensei, airin sensei, shiki dancer, shiki souran..abdi,gek,krisna, pkoknya semuanya - feeling wonderful at Gedung Pers K.Nadha.

'Arigatou Pastiarini Nyoman sensei atas bimbingan drama ny slama beberapa bln ini arigatou Fitria Nakamura sensei dan satoshi san sudah di bantu buat video dramanya. smoga hasilny bagus ya ...jd gak sbar nton video ny terima kasih atas jerih payahnya ..men sari, pan sari, nengah kun, luh, mang, yun, rin, nana, anjani, yuna, yuri sensei, airin sensei, shiki dancer, shiki souran..abdi,gek,krisna, pkoknya semuanya - feeling wonderful at Gedung Pers K.Nadha'

Data 14 merupakan status yang diunggah di facebook oleh Yunita. Statusnya merupakan ucapan terima kasih yang ditujukan kepada dosen pembimbing drama yang ia dan temannya dilakoni oleh mereka, fotografer yang mengambilkan video saat pentas drama berlangsung, dan semua temannya yang terlibat dalam drama tersebut. Yunita memasukkan ungkapan minasan ostsukaresama deshita 'terima kasih atas jerih parah semuanya'. Otsukaresama deshita merupakan sebuah ungkapan yang diucapkan oleh orang Jepang ketika selesai melakukan sesuatu. Ungkapan ini ditujukan kepada orang-orang yang diajak melakukan sesuatu itu. Penggunaan huruf kanji pada klausa minasan ostsukaresama deshita disebabkan oleh klausa tersebut terbentuk dari kata asli bahasa Jepang. 
Selain data yang telah dianalisis di atas, terdapat beberapa data campur kode pada tataran klausa yang ditemukan, seperti tabel berikut.

Tabel 3 Campur Kode Bahasa Jepang pada Tataran Klausa

\begin{tabular}{|c|c|c|c|c|}
\hline $\mathbf{N}$ & $\begin{array}{l}\text { Unsur } \\
\text { bahasa } \\
\text { Jepang yang } \\
\text { dicampurko } \\
\text { dekan }\end{array}$ & $\begin{array}{l}\text { Arti dalam } \\
\text { bahasa } \\
\text { Indonesia }\end{array}$ & $\begin{array}{l}\text { Pengung } \\
\text { gah }\end{array}$ & $\begin{array}{l}\text { Tanggal } \\
\text { dan } \\
\text { tahun } \\
\text { mengung } \\
\text { gah } \\
\end{array}$ \\
\hline 1 & $\begin{array}{l}\text { demo, } \\
\text { tanoshikatta! }\end{array}$ & $\begin{array}{l}\text { tetapi, } \\
\text { menyenangka } \\
\text { n }\end{array}$ & 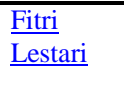 & $\begin{array}{l}21 \text { April } \\
2014\end{array}$ \\
\hline 2 & hitori jyanai! & tidak sendiri & $\begin{array}{l}\text { Yukari } \\
\text { Yabuhiro } \\
\text { ta }\end{array}$ & $\begin{array}{l}20 \quad \text { Mei } \\
2014\end{array}$ \\
\hline 3 & $\begin{array}{l}\text { shinpai } \\
\text { shinaide! }\end{array}$ & $\begin{array}{l}\text { jangan } \\
\text { khawatir }\end{array}$ & $\begin{array}{l}\text { Yukari } \\
\text { Yabuhiro } \\
\text { ta }\end{array}$ & $\begin{array}{l}16 \text { Mei } \\
2014\end{array}$ \\
\hline 4 & $\begin{array}{l}\text { otanjoubi } \\
\text { omedetou } \\
\text { gozaimasu. }\end{array}$ & $\begin{array}{l}\text { Selamat ulang } \\
\text { tahun }\end{array}$ & $\begin{array}{l}\text { Agung } \\
\underline{\text { Dian }} \\
\frac{\text { Andriyan }}{\underline{\mathrm{i}}}\end{array}$ & $\begin{array}{l}10 \text { Mei } \\
2014\end{array}$ \\
\hline 5 & $\begin{array}{ll}\text { ningen } & \text { wa } \\
\text { betsu } & \text { no } \\
\text { kanosei } & \text { ga } \\
\text { aru kara } & \end{array}$ & $\begin{array}{l}\text { karena } \\
\text { manusia } \\
\text { mempunyai } \\
\text { kemungkinan } \\
\text { lain }\end{array}$ & $\begin{array}{l}\text { Wiwien } \\
\text { Hime }\end{array}$ & $\begin{array}{l}25 \text { Mei } \\
2014\end{array}$ \\
\hline
\end{tabular}

Berdasarkan pengamatan terhadap data di atas dapat disimpulkan bahwa campur kode yang terjadi merupakan campur kode ke luar (outer code mixing). Bahasa pokok dari data di atas adalah bahasa Indonesia yang dicampurkan dengan kode bahasa Jepang, baik kata, frasa, maupun klausa sehingga jenis campur kode yang terjadi adalah campur kode kata, frase, dan klausa.

\section{Faktor-Faktor yang Memengaruhi Campur Kode Bahasa Jepang oleh Penutur Bahasa Indonesia di Jejaring Sosial Facebook}

Secara umum faktor-faktor yang memengaruhi sebuah campur kode disebabkan oleh faktor penutur dan faktor kebahasaan. Dalam penelitian ini faktorfaktor penyebab terjadinya campur kode bahasa Jepang oleh penutur bahasa Indonesia di jejaring sosial facebook diperoleh dari jawaban sebagian besar informan yang diambil status ataupun komentarnya di facebook. Peneliti mengirim beberapa daftar tanyaan kepada informan melalui online facebook.

Dilihat dari data yang diperoleh terhadap jawaban daftar tanyaan mengapa mereka cenderung mencampurkodekan bahasa Jepang dalam tuturannya dan pengamatan terhadap data primer, dapat ditarik simpulan bahwa faktor penyebab campur kode tersebut adalah sebagai berikut. Pertama, penutur ingin mempraktikkan bahasa Jepang yang telah dipelajari. Kedua, terdapat unsur bahasa Jepang yang tidak bisa diinterpretasikan $100 \%$ ke dalam bahasa Indonesia. ketiga, penutur satu komunitas dengan orang yang diajak berkomunikasi. Keempat, dengan mecampurkodekan bahasa Jepang dapat memancing mitra tutur untuk menggunakan bahasa Jepang. kelima, agar lebih keren. Keenam, ada beberapa kata yang kurang sopan akan terkesan lebih sopan jika menggunakan bahasa Jepang daripada bahasa Indonesia. Misalnya kata baka yang artinya bodoh/bego dalam bahasa Indonesia. Jadi, kesannya lebih kasar kalau yang digunakan kata bego lu, dibandingkan dengan baka itu sendiri. Dengan kata lain untuk menghindari kevulgaran. Ketujuh, hal-hal yang dikomentari mengandung unsur Jepangnya

\section{SIMPULAN}

Berdasarkan hasil analisis data tentang campur kode bahasa Jepang oleh penutur bahasa Indonesia di jejaring sosial facebook dapat disimpulkan bahwa campur kode yang terjadi ditinjau dari unsur bahasa serapan yang digunakan adalah campur kode ke luar (outer code mixing), sedangkan ditinjau dari tata tingkat perangkat kebahasaan adalah campur kode pada tataran kata, campur kode pada tataran frasa, dan campur kode pada 
tataran klausa. Faktor-faktor yang memengaruhi peristiwa campur kode, antara lain (1) penutur ingin mempraktikkan bahasa Jepang; (2) terdapat unsur bahasa Jepang yang tidak bisa diinterpretasikan 100 $\%$ ke dalam bahasa Indonesia; (3) penutur satu komunitas dengan mitra tutur; (4) dapat memancing mitra tutur untuk menggunakan bahasa Jepang; (5) agar lebih keren; (6) Menghindari kevulgaran, dan (7) hal-hal yang dikomunikasikan berkaitan dengan Jepang.

\section{DAFTAR PUSTAKA}

Chaer, A. 2007. Linguistik Umum. Jakarta: Rineka Cipta.

Fasold. R. 1984. The Sociolinguistics of Society. New York: Blackwell.

Hudson, R.A. 1991. Sociolinguistics. Cambridge: Cambridge University Press. Ibrahim, S. Abd. 1993: Kapita Selekta: Sosiolinguistik. Surabaya: Usaha Nasional. Jendra, I W. 1991. Dasar-Dasar Sosiolinguitik. Denpasar: Ikayana Denpasar. Kridalaksana, H. 2008. Kamus Liguistik. Jakarta: PT Gramedia Pustaka Utama. Mastoyo, Tri. 2007. Pengantar (Metode) Penelitian Bahasa. Yogyakarta: Carasvatibooks.

Matsuura, K. 2005. Kamus BI Jepang. Jakarta: PT Gramedia Pustaka Ut.

Nababan, P. W. P. 1993. Sosiolinguistik: Suatu Pengantar. Jakarta: PT Gramedia Pustaka Utama.

Sudaryanto. 1988. Metode Linguistik. Bagian Kedua. Metode dan Aneka Teknik Pengumpula Data. Yogyakarta: Gadjah Mada University Press.

Sudaryanto. 1993. Metode dan Aneka Teknik Analisis Bahasa. Yogyakarta: Gadjah Mada University Press.

Sudjianto dan Ahmad D. 2004. Pengantar Linguistik Bahasa Jepang. Jakarta: Oriental.
Sutedi, D. 2008. Dasar-dassar Liguistik Bahasa Jepang. Bandung: Humaniora.

Tsujimura, N. 1996. An Intoduction to Japanese Linguistics. Malaysia: Wiley Blackwell.

Wardhaugh, Ronald. 1986. An introduction to Sociolinguistics. Great Britain: Page Bross.

Widjaja, H.A.W. 2010 (Cetakan Keenam). Komunikasi: Komunikasi dan Hubungan Masyrakat. Jakarta: PT Bumi Aksara. 